Journal of Thermal Engineering, Vol. 6, No. 4, pp. 440-459, July, 2020

Yildiz Technical University Press, Istanbul, Turkey

\title{
ANALYSIS AND OPTIMIZATION OF VAPOR ABSORPTION GENERATOR-HEAT EXCHANGER USING KERN METHOD AND CFD
}

\author{
Salem Alabd Mohamed ${ }^{1, *}$, Munawar Nawab Karimi ${ }^{1}$
}

\begin{abstract}
The growing demand for new and eco-friendly energy resources has raised the need of sustainable sources or renewable energy for use in present era. A vapor absorption refrigeration system (VARS or VAS) is a closed loop refrigeration system which requires low heat for its functioning and, it is therefore, considered an eco-friendly solution. Since, generator is the main component of VAS which can significantly influence the efficacy of overall system, the current paper involves modeling and thermal analysis of generator using Computational Fluid Dynamics (CFD). The objective of this study is to optimize the heat transfer by changing baffle spacing of generator heat exchanger, running on a single effect $\mathrm{LiBr} /$ water absorption cycle. For this purpose, hot water driven generator of 1 ton capacity is taken. The simulation results of CFD were validated by comparing them with theoretical results. The overall design estimation and design technique that follows Birmingham Wire Gauge (BWG) and Tubular Exchangers Manufacturers Association (TEMA) standard are considered in this study. It was found from the analysis that the design model with smallest baffle spacing has the highest heat transfer coefficient. On reducing the baffle spacing from $137 \mathrm{~mm}$ to $101 \mathrm{~mm}$, an increment of $48 \%$ in overall heat transfer coefficient was observed. Likewise, an increase in velocity by $36 \%$ and drop in static pressure by $27 \%$ were seen. Similar trend was observed in the theoretical results.
\end{abstract}

Keywords: Vapor Absorption System (VAS), Generator, Lithium Bromide-Water Solution, Kern Method, Computational Fluid Dynamics (CFD)

\section{INTRODUCTION}

Generator heat exchanger is the important component in Vapour Absorption System (VAS). It is a reasonable way of consuming little score energy immediately for air conditioning purpose. This is the main advantage as compared to the conventional Vapour Compression System which drives in height score energy. Additional important feature of this system is that it does not use any moving part except for a very small liquid solution pump. The system contains of four basic components viz. an evaporator, an absorber (placed on low pressure side), a generator and a condenser, (placed on high pressure side). By using lithium bromide water solution $\left(\mathrm{LiBr} / \mathrm{H}_{2} \mathrm{O}\right)$ as working fluid (refrigerant), the generator creates the same duty as of the compressor in the conventional compression refrigeration cycle. The generator used to evaporate the mixture of water that reacts with lithium bromide and leaves pure water (steam). In the generator a mixture of $\mathrm{LiBr} / \mathrm{H}_{2} \mathrm{O}$ is heated. The external source of heat can be steam, hot water or any other appropriate source. The boiling point of water is lower than $\mathrm{LiBr}$, so it vaporizes, separating the refrigerant from the generator.

Due to heating, the temperature of the solution rises. The refrigerant in the solution gets evaporated and it leaves the solution at high pressure. The high pressure and temperature refrigerant then move in the condenser, where it is cooled by the coolant. It then enters the expansion valve due to which the pressure reduces and then finally, it goes into the evaporator where it produces the cooling effect. This refrigerant is then again absorbed by the weak solution in the absorber. When the vaporized refrigerant leaves the generator, weak solution is left back. This solution enters the pressure reducing valve and then back to the absorber, where it is ready to absorb fresh refrigerant. After absorption process the strong solution is pumped to the generator. This cycle is keeps repeating.

\footnotetext{
This paper was recommended for publication in revised form by Regional Editor Mohammad Safaei

${ }^{1}$ Department of Mechanical Engineering, Jamia Millia Islamia, New Delhi, India

*E-mail address: salem3375@gmail.com

Orcid id: 0000-0001-6345-4454, 0000-0002-9411-3422

Manuscript Received 14 February 2020, Accepted 4 May 2020
} 
The pressure of the refrigerant is increased in the generator and hence it is considered to be equivalent to the compressor.

A vapor absorption refrigeration system is a closed loop refrigeration system which requires low heat for its functioning or air conditioning purpose [1] and, it is therefore, considered an eco-friendly solution. However, it has relatively poor cooling efficiency, with its Coefficient of Performance (COP) typically lying in the range 0.5 and 1.5, compared to modern vapor compression cycles having COP of 3.0 or more [2]. This limits its application on side, but due to its advantage on the other side for using low temperature (normally below 1000C) heat to provide cooling, while making use of low temperature heat, which otherwise, is considered waste for other processes. This is helpful in enhancing overall energy efficiency of the system, by making use of unused energy of the system [3, 4]. The VAS system may comprise of single, double, or even triple effect. In multi-effect cycle more components are required with higher temperature of waste heat, but they have relatively higher COP [5].

The growing demand for new and eco-friendly energy resources has raised the need of sustainable sources or renewable energy for use in present era. S. Hoseinzadeh et al. [6] performed feasibility study of zero energy buildings (ZEBs), supporting the usage of renewable energies, essential for sustainable development, yielding minimal production of greenhouse gases.

Latent heat is one efficient way to store energy which produces a high-density energy reserve using small temperature differences. S. Hoseinzadeh et al. [7] analyzed the effect of geometrical parameters of storage via twodimensional numerical investigation of the performance of the Latent heat thermal storage (LHTS) unit, comprising several rectangular PCM slabs. Similar other work on numerical and analytical investigation of thermal properties have been reported for different thermal systems. In literature [8-9], authors have analyzed heat transfer (convective-radiative) characteristics of porous fins with rectangular cross section. The effect of different parameters like, porosity and convection, were examined.

The concept of VAS was first discovered by Michael Faraday in 1824 while performing a set of experiments to liquify certain gases. The first vapour absorption refrigeration machine was developed by a French scientist Ferdinand Carre in 1860. This system may be used in both the domestic and large industrial refrigerating plants. The issue related to the phase changing is well referred in Stefan problems. Although using latent heat is helpful in terms of energy density, the phase-changing constituents often suffer from short heat transfer due to their properties, system design, heat transfer area. To overcome this insufficiency, some analyses and studies have been reported related to the performance or heat transfer rate. For example, Elgafy et al. [10] studied matrix with a high heat transfer. R. Ghasemiasl et al. [11] studied the influence of adding nanoparticles to copper and alumina for improving the system performance of phase change. Esmaeil et al. [12] modelled thermal energy generated by the collector. Hoseinzadeh et al. [13] designed absorption chiller and the solar collector area for meeting cooling load. H. Kariman et al. [14] thermodynamically optimized desalination using a forced rotation of the energy of distilled water into saline water to maximize the use of available energy and decrease the energy consumption. The use of vacuum pressure for achieving phase changing in low temperature was also studied in few papers. H. Kariman et al. [15] modelled evaporative vacuum desalination system with brine tank for energy consumption. S. Hoseinzadeh et al. [16] performed an investigation and found that the heat transfer of laminar and turbulent pulsating $\mathrm{Al}_{2} \mathrm{O}_{3} /$ water nanofluid flow in a two-dimensional channel, the velocity magnitude increased during laminar flow range, with increasing Reynolds number (Re). Similarly, the Nusselt number $(\mathrm{Nu})$ was improved, because of increase the overall heat transfer rate. In another investigation, $\mathrm{S}$. Hoseinzadeh et al. [17] studied the effect of $\mathrm{SiC}$ and $\mathrm{Al}_{2} \mathrm{O}_{3}$ nanoparticles on thermal efficiency of thermosyphon. It was observed that by adding $\mathrm{SiC}$ and $\mathrm{Al}_{2} \mathrm{O}_{3}$ nanoparticles to water, the temperature difference between the condenser and evaporator was decreased, which confirmed the improved efficiency of thermosyphon. In [18], an experimental investigation on thermal performance and pressure drop of a microchannel heat sink under the low heat flux condition, copper oxide nanoparticles were added to the liquid at $170{ }^{\circ} \mathrm{C}$ to escape from frosting. Sarafraz et al. [19] concluded that through this method a greater heat transfer coefficient was realized. Also, experimental study on the convective heat transfer of graphene nano-platelets dispersed in water-ethylene glycol showed that graphene nano-suspension was working as a coolant inside a microchannel [20]. Also, method of using graphene nano-platelets can possibly improve the thermal conductivity of the 
working fluid. It was identified that the thermal performance of the system improved but, with rise in the pressure drop value [21]. It was established through experimental studies on boiling mechanism of a disc copper made heater at different heat flux, mass concentration of nano-fluids and sub-cooling temperatures. The study proved that heat transfer coefficient of Titana nano-fluids are comparatively better than that of the base fluid. Sarafraz et al. [22] obtained that in attendance of surfactant, higher pool boiling heat transfer coefficient was improved. According to their report, the smoothness of surface is powerfully controlled by nanofluid concentration due to deposition of nanofluids on the heating division. Robert et al. [23] found this article were in good approval with other literature review which offer development using nanofluids with changes in the surface play in pool boiling the most imperative part in defining whether enhancement is realized.

In current study though nanofluid has not been used in this system in order to avoid chemical reaction due to using $\mathrm{LiBr} / \mathrm{H}_{2} \mathrm{O}$. Practical problem typical to lithium-bromide water-based VAS is phase changing (steam generation). As we know the system is closed loop and is completely independent of the external heat sources. To minimize the external heat supplied or energy consumption, the efficiency of the system should be improved to achieve phase changing. This is done by increase the heat transfer in generator, whereas, pressure and temperature have to be maintained at certain level.

Since, generator is the main component of VAS which can significantly influence the efficacy of overall system, the current paper involves modeling and thermal analysis of generator using Computational Fluid Dynamics (CFD) wherein a single effect $\mathrm{LiBr} /$ water absorption cycle has been considered. The objective of this study is to optimize the heat transfer by changing baffle spacing of generator heat exchanger. For this, hot water driven generator of 1 ton capacity is taken. The theoretical results were obtained using Kern method and they were compared with the simulation results of CFD. The heat exchanger comprising of single shell and double tube in vertical disposition, with $25 \%$ baffles cut were taken with varying baffle spacing as: $139 \mathrm{~mm}, 127 \mathrm{~mm}, 110 \mathrm{~mm}$ and $101 \mathrm{~mm}$. The overall designing estimation and design technique that follows Birmingham Wire Gauge (BWG) and Tubular Exchangers Manufacturers Association (TEMA) standard are considered in this study. This paper has been organized into the following four major sections: Section 1 describes briefly about the Vapor Absorption System and its functioning. Section 2 contains the design methodology adopted in this work. Section 3 shows the results obtained from the theoretical and the simulation methods, followed by comparison between the two. Finally, section 4 provides the conclusion of the current study.

\section{DESIGN METHODOLOGY Heat transfer in generator of VAS}

The generator heat exchanger of single effect $\mathrm{LiBr} / \mathrm{H}_{2} \mathrm{O}$ absorption refrigeration system comprises of a shelland-tube heat exchanger. The generator is in vertical orientation with an inlet, two outlets, an inner and outer shell. The strong solution enters into the inner shell directly from the inlet at the top of generator, and then moves between the baffle plates around the tubes and get heated up via absorption of heat from hot fluid which passes in tubes. When the solution reach at the bottom, the water vaporizes. The inner shell opens to outer shell at the bottom. The weak solution is discharged from the generator at the bottom outlet and from there it is returned back to the absorber, where it becomes ready to absorb fresh refrigerant. When the steam passes between the inner and outer shell, it absorbs more heat until discharge from outlet at the top of generator and passes to the condenser. By adding the outer shell, we can allow the steam to rise upward to discharge from the top, without restriction to the solution to pass in the opposite direction. In this way, the refrigerant keeps on repeatedly moving inside the cycle. In this section all the fundamental equations related to the modeling of generator of VAS have been provided. For cooling of chiller generator lithium bromide water system $4.6 \mathrm{~kW} / \mathrm{TR}$ of heat is supplied [24]. The mass flow rate $\left(\dot{\mathrm{m}}_{h}\right)$ of the hot fluid (water) can be obtained from heat transfer rate $(q)$ using overall energy balance equation [25]:

$$
q=\dot{\mathrm{m}}_{h} C_{p h}\left(T_{h, i}-T_{h, o}\right)
$$


where, $T_{h, i}$ and $T_{h, o}$ represents temperature of hot fluid at inlet and outlet, respectively, and $C_{p, h}$ is the specific heat of hot fluid at constant pressure.

The temperature $\left(T_{c, o}\right)$ of the cold fluid at outlet (solution of $\mathrm{LiBr}$ - Water) can therefore be obtained using Eq. (2) [25]:

$$
T_{c, o}=\frac{q}{\dot{\mathrm{m}}_{c} C_{p, c}}+T_{C, i}
$$

where, $T_{c, i}$ represents temperature of cold fluid at inlet, $C_{p, c}$ is the specific heat of cold fluid at constant pressure, flowing with mass flow rate $\left(\dot{\mathrm{m}}_{c}\right)$.

\section{Kern Method:}

The heat transfer area $(A)$ can be determined from Eq. (3) [26]:

$$
A=\frac{Q}{U_{a s s m} \Delta T_{i m} F_{T}}
$$

where, $A$ is the total area of hot fluid-side or cold fluid-side for heat transfer, $U$ is the average overall heat transfer coefficient and $\Delta T_{i m}$ is a function of hot and cold fluid temperature at input and output, respectively symbolized as: $T_{h, i}, T_{h, 0}, T_{c, i}, T_{c, o}$.

The LMTD (Log Mean Temperature Difference) method is a convenient way for finding the size of a heat exchanger (generator in our case), for a given value of input and output temperatures of the hot (water) and cold $\left(\mathrm{LiBr} / \mathrm{H}_{2} \mathrm{O}\right)$ fluids, and can be calculated using Eq. (4) $[25,26]$ :

$$
\Delta T_{l m}=\frac{\left(T_{h, i}-T_{C, o}\right)-\left(T_{h, o}-T_{C, i}\right)}{\ln \left[\left(T_{h, i}-T_{C, o}\right) /\left(T_{h, o}-T_{C, i}\right)\right]}
$$

For multi-pass, crossflow the correction factor $\left(\mathrm{F}_{\mathrm{T}}\right)$ of heat exchanger is used to rectify the $\log$ mean temperature difference. Reference [24] can be referred for values of one shell and two or more tube passes). The value of overall heat transfer coefficient $\left(U_{\text {assm }}\right)$ of $250 \mathrm{w} / \mathrm{m}^{2} \mathrm{~K}$ is taken to begin the design calculation for the lithium bromide water solution and hot water for generator heat exchanger. The approximate range of the overall heat transfer coefficient depends upon temperature difference between the fluids, and it can be found out from reference [25].

The number of tubes $\left(n_{t}\right)$ required for heat transfer can be calculated using following Eq. (5) [26]:

$$
n_{t}=\frac{A}{\pi d_{o} L_{t}}
$$

where, $d_{o}$ and $L_{t}$ are the outside diameter and length of tube.

The overall heat transfer coefficient $U_{o, c a l}$ is dependent upon the physical properties of the fluid and its physical state. The expression for $U_{o, c a l}$ is given by Eq. (6):

$$
U_{o . c a l}=\left[\frac{1}{h_{o}}+R_{d s}+\frac{A_{o}}{A_{i}}\left(\frac{d_{o}-d_{i}}{2 k_{w}}\right)+\frac{A_{o}}{A_{i}}\left(\frac{1}{h_{i}}\right)+\frac{A_{o}}{A_{i}} R_{d h}\right]
$$

The convective heat transfer coefficient, $h_{i}$ and $h_{o}$ at the tube side and the shell side, respectively, can be calculated using Eq. (9) and Eq. (12) [26,27].

Next, the Reynold's number for the hot water flowing through the tube is calculated using Eq. (7) [25]: 


$$
R e_{i}=\frac{4 \dot{\mathrm{m}}_{h}}{\pi d_{o} \mu_{i}}
$$

The empirical relation for the local Nusselt number, in case of fully developed (hydrodynamically and thermally) turbulent flow in case of a smooth circular tube, is given by Dittus-Boelter equation [27], as follow:

$$
N u_{D}=0.023 R e_{i}^{4 / 5} P_{r}^{0.4}
$$

Hence, the convective heat transfer coefficient $h_{i}$ at the tube side can be expressed as [25]:

$$
h_{i}=N u_{D} \frac{K f_{i}}{d_{i}}
$$

The Reynold's number for LiBr-water solution flowing through shell, is calculated using Eq. (10) [26]:

$$
R e_{o}=D_{e} G_{s} / \mu_{s}
$$

where the equivalent diameter, $D_{e}$ for the shell side with square pitch $P_{T}$, is obtained by Eq. (11) [26, 27]:

$$
D_{e}=4\left(P_{T}^{2}-\pi / 4 d_{o}^{2}\right) / \pi d_{o}
$$

The convective heat transfer coefficient $h_{o}$ at the shell side is calculated from Colburn factor $(j H)$, obtained from curve of shell side heat transfer for bundles with $25 \%$ cut segmental baffles at calculated value of Reynold's number $\left(R e_{o}\right)$. The relationship between $h_{o}$ and $j H$ is expressed in Eq. (12)[26, 27]:

$$
j H=\frac{h_{o} D_{e}}{k_{s}}\left[\frac{\mu_{s} C_{p, s}}{k_{s}}\right]^{-1 / 3}
$$

The clean overall heat transfer coefficient $U_{c}$ can be determined from Eq. (13) [28]:

$$
U_{c}=\frac{h_{o} x h_{i o}}{h_{o}+h_{i o}}
$$

Therefore, the calculation of overall heat transfer coefficient is within the design criteria, viz.

$$
U_{o, c a l}-U_{o, a s s m} / U_{o, a s s m \times 100} \ldots<30 \%
$$

Due to flow of the fluid through a generator, the pressure drops in downstream except for the cases with decreasing fluid velocity, wherein the pressure rises in the downstream side. The tube-side pressure drop can be calculated from Eq. (15) [28]:

$$
\Delta P_{t}=4 f_{i}\left[\frac{L N_{p}}{D_{i}}\right] \rho_{i}\left[\frac{\mu_{m}^{2}}{2}\right]
$$

The additional pressure drop due to change in the direction of the tube is calculated using Eq. (16) [28]:

$$
\Delta P_{r}=4 N_{p}\left[\frac{\rho_{i} \mu_{m}^{2}}{2}\right]
$$


The total pressure drop of tube-side is the sum of pressure drop due to friction during flow and that due to change in direction:

$$
\Delta P_{\text {total }}=\Delta P_{t}+\Delta P_{r}
$$

The shell-side pressure drop for fluid flow across the tube bundles (frictional loss) is calculated using Eq.(18)[28]:

$$
\Delta P_{s}=\frac{f_{o} G_{s}^{2}\left(N_{b}+1\right) D_{s}}{2 \rho_{o} D_{e} \phi_{s}}
$$

For overdesign calculation of extra surface area beyond what is required for compensation of fouling, a typical value of $10 \%$ or less is considered acceptable [27, 28].

$$
\% \text { Over design (od) }=A-A_{\text {reqd }} / A_{\text {reqd }} \times 100 \ldots<\% 10
$$

\section{Baffle Spacing and Baffle Cut}

The baffle spacing $\left(L_{B}\right)$ is the center-to-center distance between adjacent baffles, as shown in Figure 1.

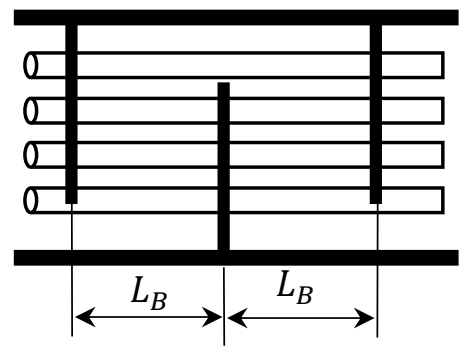

Figure 1. Layout of generator heat exchanger showing baffle spacing $L_{B}$

The baffle spacing is one of the most critical geometric parameters that affects both the pressure drop and the heat transfer characteristics of shell side model. By changing the baffle spacing, the mass velocity and the counter flow area of the shell side fluid is changed which ultimately changes the heat transfer. For smaller baffle distance, the flow area is smaller, and the fluid velocity is higher. The high flow velocity means there is slight increase in the frictional pressure drop along with the heat transfer coefficient. Although, the heat transfer coefficient is increased when the baffle distance is reduced, the TEMA has set a standard for its lower limit to be 0.2 to 1 times of the inside shell diameter $\left(D_{s}\right)$. Similarly, when the baffle distance is high, the heat transfer coefficient is low. Moreover, higher baffle distance also give rise to longitudinal flow which is considered less efficient compared to cross flow. This also leads to lesser unsupported tube length which makes the design less strong and more prone to failure due to buckling and vibration. Hence, TEMA has set the standard for maximum baffle spacing for mechanical considerations. In generator heat exchanger model, the baffle spacing therefore should be chosen so that it may ensure sufficient support to the tubes within the shell, besides, achieving the highest possible amount of the heat transfer rate within prescribed pressure drop limit. The baffle cut from $15 \%$ to $45 \%$ is generally used, but 20 to $25 \%$ provides perfect heat transfer with a slight pressure drop resulting due to frictional losses. This is because, in case of small cut for segmental plates (baffles), the shell side fluid flow turbulence is high which results in high fluid velocity and consequently increases the heat transfer coefficient. Contrary to this, in case of large baffle cut, the velocity is low and hence the heat transfer coefficient is also low [5]. In the current study, a baffle cut of $25 \%$ has been taken for four different baffle spacings, from $40 \%$ to $55 \%$ of the inside shell diameter specifically as: $139 \mathrm{~mm}$, $127 \mathrm{~mm}, 110 \mathrm{~mm}$ and $101 \mathrm{~mm}$. 


\section{D MODELING}

The 3-D model of the generator was first created in Solid Works, as shown in figure 2. Figure 2a and Figure $2 \mathrm{~b}$ shows full and cut section of one of the generator models, respectively. The inlet and outlet for $\mathrm{LiBr}$ water solution as well the hot water can be seen in Figure 2a. The cut section presented in Figure $2 \mathrm{~b}$ displays the disposition of the tubes and baffles inside the shell of the generator heat exchanger.
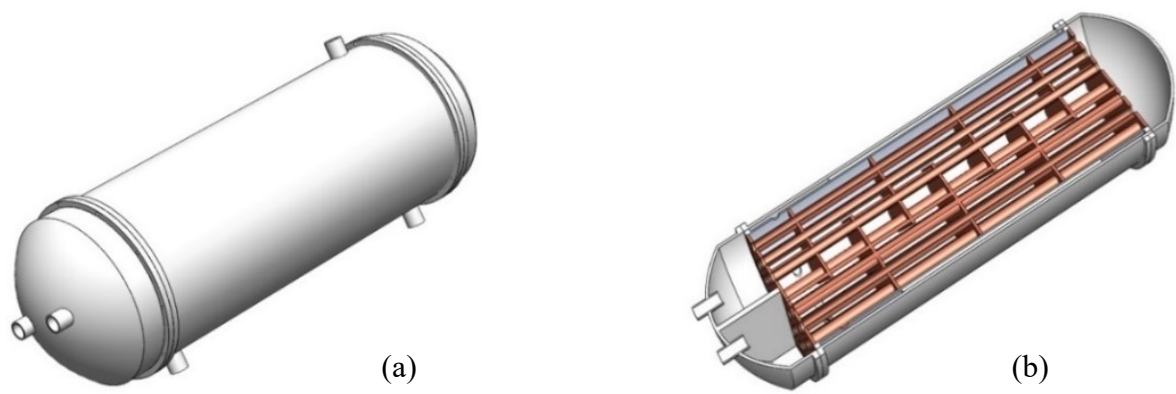

Figure 2. 3-D modeling with (a) full isometric view (b) cut section view

Figure 3 shows the drawings of all the four models with major geometrical dimensions, considered in the current study for analysis of generator heat exchanger.

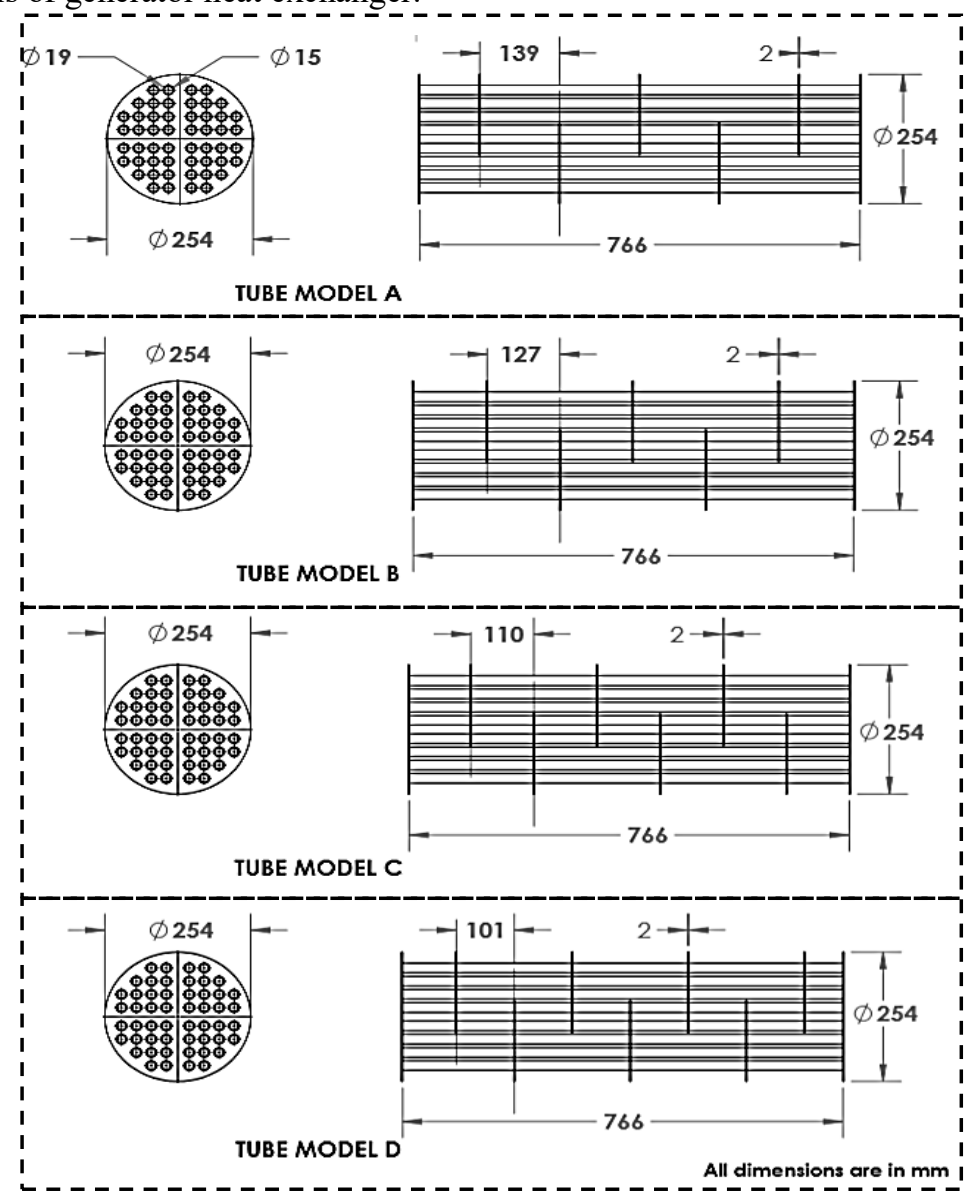

Figure 3. Drawings of all the four generator models with different baffle spacing: $L_{B}=139 \mathrm{~mm}, 127 \mathrm{~mm}, 110 \mathrm{~mm}$ and $101 \mathrm{~mm}$ for model $\mathrm{A}, \mathrm{B}, \mathrm{C}$ and $\mathrm{D}$, respectively.

The different baffle spacings $\left(\mathrm{L}_{\mathrm{B}}\right)$ were $139 \mathrm{~mm}, 127 \mathrm{~mm}, 110 \mathrm{~mm}$ and $101 \mathrm{~mm}$ for model A, B, C and D, respectively, which can be seen clearly from the drawings. The model contains 52 copper tubes with inner diameter 
Journal of Thermal Engineering, Research Article, Vol. 6, No. 4, pp. 440-459, July, 2020

of $15.95 \mathrm{~mm}$. The number of fluid passes in tubes side $\left(\mathrm{N}_{\mathrm{p}}\right)$ is 2 , the square pitch (PT) is $25 \mathrm{~mm}$, corresponding to the closest standard (BWG). The length of the tubes $\left(\mathrm{L}_{\mathrm{t}}\right)$ is $766 \mathrm{~mm}$ and the baffle plates thickness is $2 \mathrm{~mm}$, which is same in all the four models, while the variable $\left(L_{B}\right)$, during a drop in baffles space, increases in number of baffles plate $\left(\mathrm{N}_{\mathrm{b}}\right)$. Model A and B have 5 baffle plates, whereas Model C and Model D have 6 and 7 plates, respectively.

\section{CFD AND THEORETICAL ANALYSIS Theoretical Analysis}

The Table 1 and Table 2 shows the modeling data for working fluid and properties of lithium bromide/ water solution, used in the current study as the working fluid, required for theoretical calculation for tube side.

Table 1. Modeling Data for working fluid

\begin{tabular}{|l|c|c|}
\hline \multicolumn{1}{|c|}{ Data } & Tube side & Shell side \\
\hline Fluid Name & Water $\left(\mathrm{H}_{2} \mathrm{O}\right)$ & $\mathrm{LiBr}+\mathrm{H}_{2} \mathrm{O}$ \\
\hline Input Temperature $\left({ }^{\circ} \mathrm{C}\right)$ & 100 & 40 \\
\hline Output Temperature $\left({ }^{\circ} \mathrm{C}\right)$ & 65 & 97 \\
\hline Mass Flow rate $(\mathrm{kg} / \mathrm{s})$ & 0.0313 & 0.0212 \\
\hline Inner Diameter $(\mathrm{m})$ & 0.015 & 0.245 \\
\hline Outer Diameter $(\mathrm{m})$ & 0.019 & -- \\
\hline Length $(\mathrm{m})$ & 0.766 & -- \\
\hline Heat supplied in Generator $\left(\mathrm{Q}_{\mathrm{G}}\right)$ in $\mathrm{kW}$ & 4.6 & -- \\
\hline Input Pressure $(\mathrm{psi})$ & 14.5 & 1.0697 \\
\hline
\end{tabular}

Table 2. Properties of Water and Lithium bromide water solution at average temperature [29, 30]

\begin{tabular}{|l|c|c|}
\hline Property of the Fluid & Hot Water & LiBr/ water Solution \\
\hline Average Temperature $\left({ }^{\circ} \mathrm{C}\right)$ & 82.5 & 68.5 \\
\hline Specific Heat $\left(\mathrm{J} \mathrm{kg}^{-1} \mathrm{~K}\right)$ & $4.196 \times 10^{-3}$ & $3.808 \times 10^{-3}$ \\
\hline Thermal Conductivity $(\mathrm{W} / \mathrm{m} \mathrm{K})$ & $0.667 \times 10^{-3}$ & $0.512 \times 10^{-3}$ \\
\hline Density $\left(\mathrm{kg} / \mathrm{m}^{-3}\right)$ & 971.82 & 1433 \\
\hline Dynamic Viscosity $\left(\mathrm{Ns} / \mathrm{m}^{2}\right)$ & $0.355 \times 10^{-3}$ & $0.4016 \times 10^{-3}$ \\
\hline Prandtl Number & 2.266 & -- \\
\hline
\end{tabular}

It is assumed that the plates and tubes are fixed. The following values for conducting analysis were taken corresponding to the closest standard (BWG), [26]:

- $\quad 3 / 4$ OD tube $(11 \mathrm{BWG})$ on 1 square pitch $\left(P_{T}\right)$

- Tube length $\left(L_{t}\right)=26$ inch

- 1 shell pass- 2 tube passes

- Tube ID $=0.510$ inch

- Flow area per tube $=0.204$ in $^{2}$

- Shell $\mathrm{ID}=10$ inch

- Number of the tube $=52$

The system of equations presented previous section were solved for the above parameter settings and the properties of fluid given in Table 3. 
Journal of Thermal Engineering, Research Article, Vol. 6, No. 4, pp. 440-459, July, 2020

Table 3. Values of some constants for fluids used in the analysis

\begin{tabular}{|l|c|l|c|l|c|}
\hline Parameters & Values & \multicolumn{1}{|c|}{ Parameters } & Values & Parameters & Values \\
\hline$\Delta T_{i m}\left({ }^{\circ} \mathrm{C}\right)$ & 10.37 & BWG- ID & 11 & $\emptyset_{s}$ & 1 shell side \\
\hline$R e_{i}$ & 8666 & $N_{p}$ & 2 & $C_{P}$ & 1square pitch \\
\hline$N u_{D}$ & 45.09 & $P_{T}(m)$ & 0.0254 & $R_{d h}$ & 0.0001 \\
\hline$h_{i}\left(\mathrm{~W} / \mathrm{m}^{2} \mathrm{~K}\right)$ & 2321.7 & $D_{s}(\mathrm{~m})$ & 0.254 & $R_{d s}$ & 0.0002 \\
\hline$\dot{\mathrm{m}}_{h}(\mathrm{~kg} / \mathrm{s})$ & 0.0313 & $L_{t}(\mathrm{~m})$ & 0.766 & $h_{\text {io }}\left(\mathrm{W} / \mathrm{m}^{2} \mathrm{~K}\right)$ & 1578.75 \\
\hline$F_{T}$ & 0.97 & $f_{i}$ & 0.01949 & $U_{o, a s s m}\left(\mathrm{~W} / \mathrm{m}^{2} \mathrm{~K}\right)$ & 250 \\
\hline$n_{t}$ & 52 & $\mu_{m}(\mathrm{~m} / \mathrm{s})$ & 0.041 & $k_{w}(W / m K)$ & 390 \\
\hline$C(m)$ & $6.35 \times 10^{-3}$ & $\Delta P_{t}(P s i)$ & 0.732 & $A\left(m^{2}\right)$ & 2 \\
\hline$L_{t t}(m)$ & 34.34 & $\Delta P_{t r}(P s i)$ & 1.6 & $A_{\text {reqd }}\left(m^{2}\right)$ & 1.83 \\
\hline$d_{i}(m)$ & 0.015954 & $\Delta P_{\text {total }}(P s i)$ & 2.3 & $n_{t, r e q d}$ & 46 \\
\hline$d_{o}(m)$ & 0.01905 & $D_{e}(m)$ & 0.0240 & $O d(\%)$ & $9.2 \%$ \\
\hline
\end{tabular}

The summary of the results so obtained have been presented in Table 4.

Table 4. Results of different models for different baffle spacing with $25 \%$ baffle cut

\begin{tabular}{|l|c|c|c|c|}
\hline \multicolumn{1}{|c|}{ Parameter } & Model A & Model B & Model C & Model D \\
\hline$L_{B}(m)$ & 0.139 & 0.127 & 0.110 & 0.101 \\
\hline$N_{b}$ & 5 & 5 & 6 & 7 \\
\hline$G_{S}\left(\mathrm{~kg} / \mathrm{m}^{2} s\right)$ & 2.401 & 2.628 & 2.928 & 3.286 \\
\hline$A_{S} \times 10^{-3}\left(\mathrm{~m}^{2}\right)$ & 8.826 & 8.065 & 7.239 & 6.4516 \\
\hline$\Delta P_{S}(P s i)$ & 0.058 & 0.062 & 0.069 & 0.076 \\
\hline$O c(\%)$ & $2.8 \%$ & $7.2 \%$ & $11.52 \%$ & $13.73 \%$ \\
\hline$O S(\%)$ & $30 \%$ & $30 \%$ & $31 \%$ & $30 \%$ \\
\hline$R e_{o}$ & 1408 & 1540 & 1716 & 1926 \\
\hline$f_{o}$ & 0.460 & 0.432 & 0.403 & 0.374 \\
\hline$h_{O}\left(\mathrm{~W} / \mathrm{m}^{2} \mathrm{~K}\right)$ & 864 & 927 & 990 & 1022 \\
\hline$U_{o, c a l}\left(\mathrm{~W} / \mathrm{m}^{2} \mathrm{~K}\right)$ & 451 & 468 & 483.6 & 499 \\
\hline$U_{c}\left(\mathrm{~W} / \mathrm{m}^{2} \mathrm{~K}\right)$ & 587 & 612 & 634 & 650 \\
\hline
\end{tabular}

As per the values obtained for convective as well as the overall heat transfer coefficient of different models, model D with the smallest baffle spacing shows the best heat transfer characteristics.

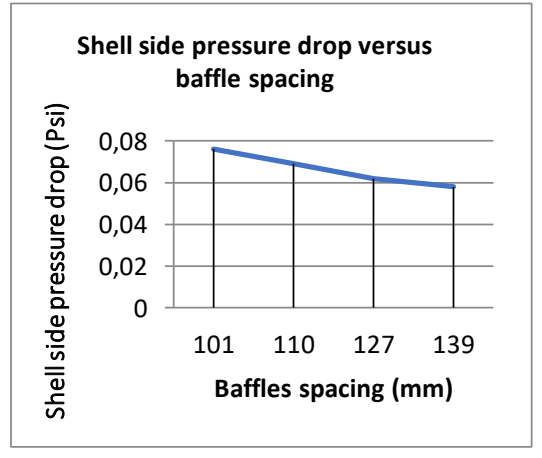

(a)

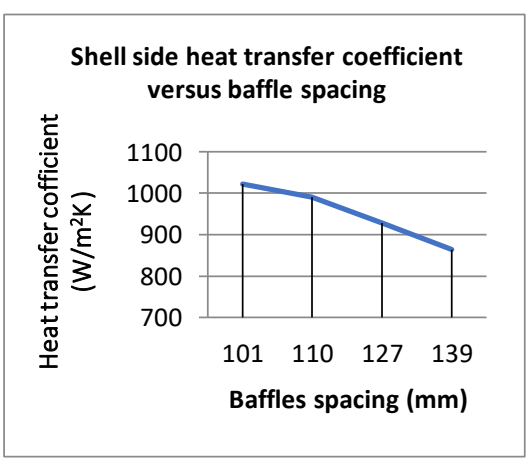

(b)

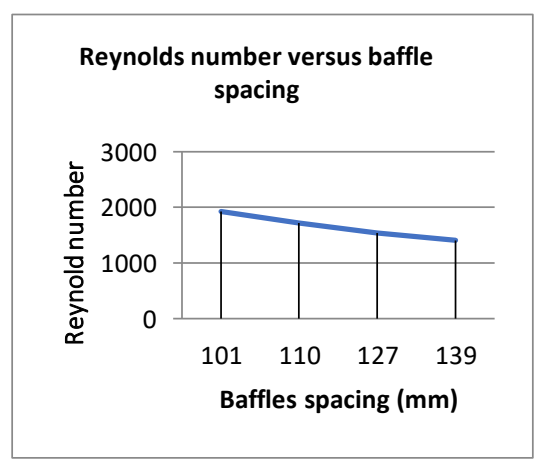

(c)

Figure 4. A comparative view of (a) the shell side pressure drop (b) heat transfer coefficient and, (c) Reynold's number for different baffle spacing. 
Figure 4 shows the summary results for different baffle spacing corresponding to different generator models namely A, B, C and D considered in the current work. Figures 4 (a), (b) and (c) shows a comparative view of the shell side pressure drop, heat transfer coefficient and Reynold's number, respectively, for different baffle spacing.

Figure 4(a) shows the effect of baffle distance on shell side pressure drop, wherein it can be seen that by increasing the baffle distance the shell side pressure drop is reduced. The highest and the lowest values of shell side pressure drop are 0.076 Psi and 0.058 Psi, corresponding to Model D and Model A, respectively. The decrease in pressure drop due to increasing baffle distance is because of smaller shell fluid mass velocity. A decrease of about $36 \%$ in shell fluid mass velocity is observed on increasing the baffle space from $101 \mathrm{~mm}$ to $139 \mathrm{~mm}$ and this amount is sufficient to decreases shell side pressure drop by $31 \%$. Figure 4(b) shows the relationship of baffle distance and shell region fluid heat transfer coefficient, wherein the high and low values of shell side heat transfer coefficient are $1022 \mathrm{~W} / \mathrm{m}^{2} \mathrm{~K}$ and $864 \mathrm{~W} / \mathrm{m}^{2} \mathrm{~K}$, corresponding to Model D and Model A, respectively. It is apparent from here that with increasing baffle space the heat transfer coefficient decreases, and this is because the increase in baffle spacing causes unsteady shell side fluid flow. Figure 4(c) shows the percentage of Reynolds number increase for different generator models. An increase of $36.7 \%$ in Reynolds number percentage is observed as we move from model A to D due to which the heat transfer is also highest in model D (because of higher turbulence).

\section{CFD Analysis \\ Geometry}

The Generator was made like a shell-tube heat exchanger on solid works and then exported in IGS file into ANSYS Fluent. In workbench stage there are some processers it was generated like united, merge and fill the surfaces inside, outside the tubes and shell domain, then finally named cell zone selection that will help for selection the special materials for every domain. $25 \%$ baffle cut was taken in the current study. Baffles spacing of $139 \mathrm{~mm}$, $127 \mathrm{~mm}, 110 \mathrm{~mm}$ and $101 \mathrm{~mm}$ for model A, B, C and D, respectively, in order to study its influence on the heat transfer rate. In order to reduce the computational time, only smaller number of tubes have been taken in the analysis part and the cover shell have been removed, ensuring that these inclusions does not affect the final analysis results. Although simulation time depends mainly on computational method and the configuration of computational hardware, the time taken in our case (double precision and 2 processes method, core i7, 200 iteration) was roughly 25 minute. Figure 5 shows the geometry of the tube-shell assembly of Model $\mathrm{C}$ of the generator, imported in ANSYS Fluid.
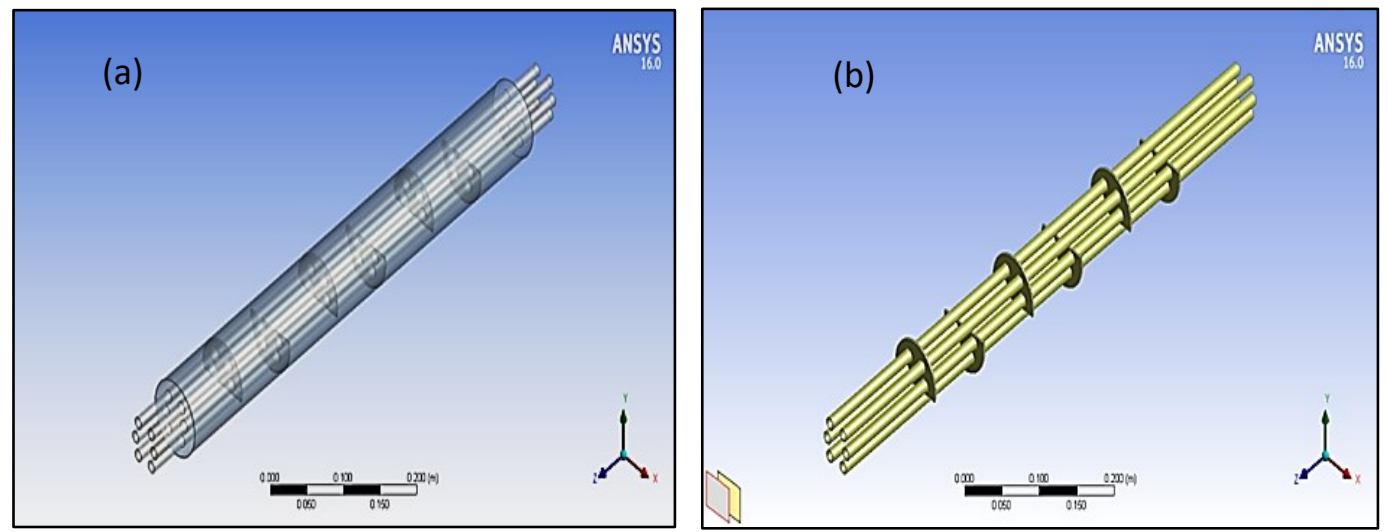

Figure 5. Geometry of the tube-shell assembly of Model C of the generator (a) with shell, (b) without shell

\section{Meshing}

Meshing is an integral part of the computer aided engineering simulation process. The mesh affects the accuracy, convergence and speed of the solution result and meshing should be done properly on the surface and edges, as per the geometry details and solution convergence. If the geometry has high number of element it will give 
more accuracy result and it can show very clear on the surface. Figure 6 shows the meshed model of generator in the ANSYS workbench, obtained using double precision and 2 processes method. The number of elements used in this meshing for different models, is shown in Table 5. In this process face meshing and edge sizing of meshing is done to analyze the process.

Table 5: Number of elements and nodes of meshing of different models

\begin{tabular}{|c|c|c|}
\hline Domain & Elements & Nodes \\
\hline Model A & 11558354 & 3363275 \\
\hline Model B & 11559492 & 3363389 \\
\hline Model C & 18193942 & 5025401 \\
\hline Model D & 40490089 & 11844561 \\
\hline
\end{tabular}

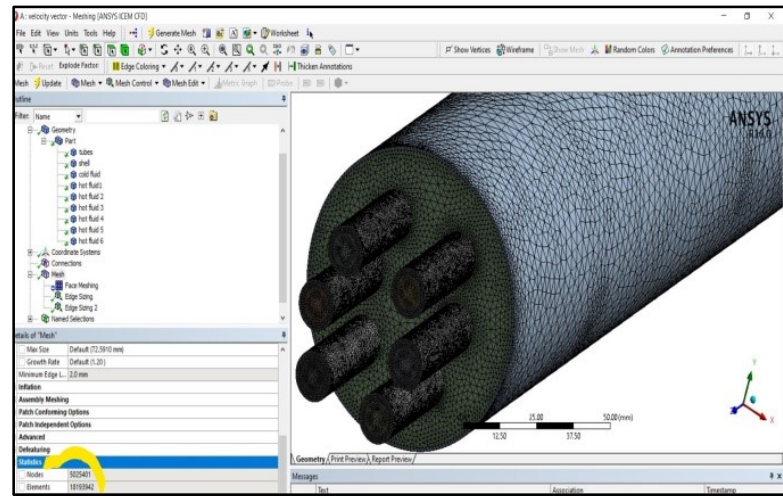

(a)

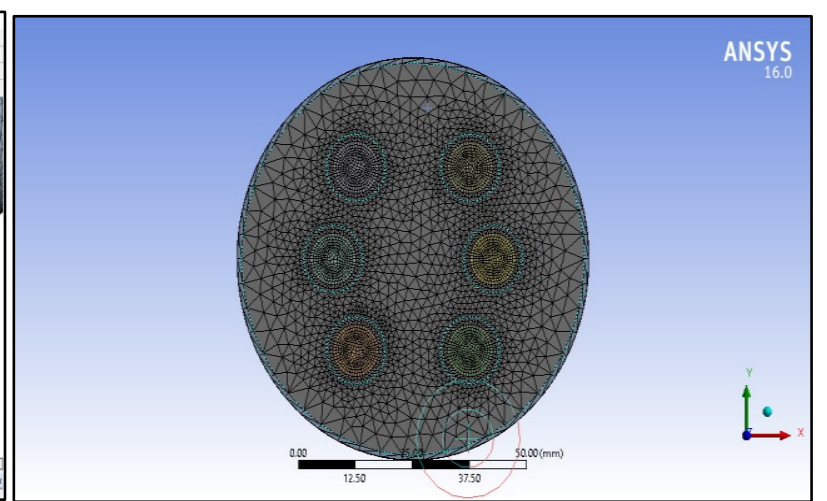

(b)

Figure 6. Meshing model of generator (a) Isometric view and (b) side view

\section{CFD Results}

The CFD model (ANSYS Fluent 16) was initially used to verify the performance of generator heat exchanger. The analysis setup based on four cell zone condition, tubes and shell solid material (copper and steel), and cold fluid $\left(\mathrm{LiBr} / \mathrm{H}_{2} \mathrm{O}\right)$ solution and hot fluid (water), this analysis done in double precision for more accuracy, under vacuum pressure the theoretical results of Table 1 and Table 2 were used as input data in boundary condition for setup stage, standard initialization method option used in solution monitors and computed from all zone condition, 100 number of iteration was taken for run calculation in CFD analysis. The baffle spacing of the different models, namely Model A, Model B, Model C, and Model D were taken as $139 \mathrm{~mm}, 127 \mathrm{~mm}, 110 \mathrm{~mm}$ and $101 \mathrm{~mm}$, respectively. With different baffle spacing the models are supposed to have different flow velocity between the baffles in shell, thereby yielding different heat transfer rate. Figure 7 for Model A, Figure 8 for Model B, Figure 9 for Model C and Figure 10 for Model D summarize a comparative result of CFD analysis for all the models showing the four critical parameters including (a) wall heat transfer coefficient, (b) stream velocity, (c) static temperature and, (d) static pressure at shell fluid side. 
Journal of Thermal Engineering, Research Article, Vol. 6, No. 4, pp. 440-459, July, 2020

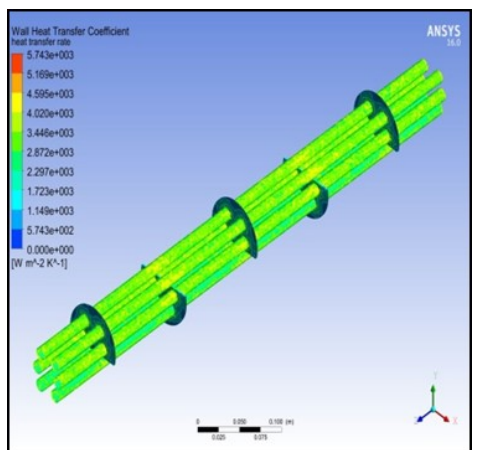

(a)

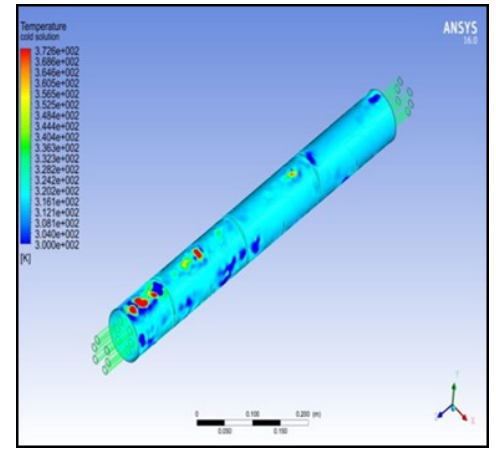

(c)

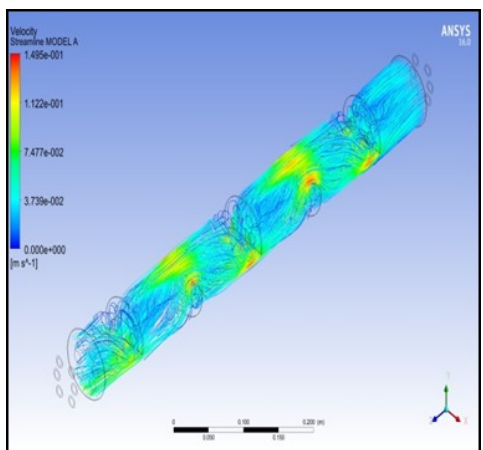

(b)

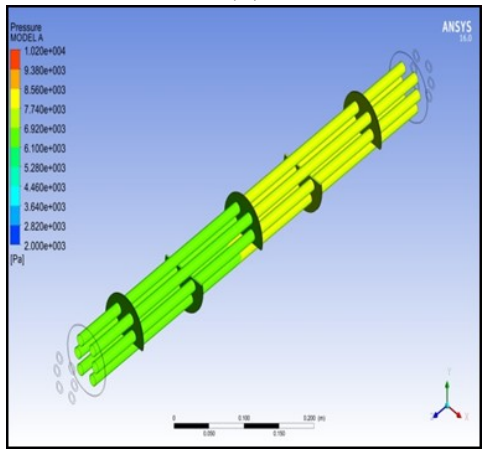

(d)

Figure 7. (a) Wall heat transfer cofficient $\left(\mathrm{W} / \mathrm{m}^{2} \mathrm{k}\right)$, (b) streamline velocity magnitude $(\mathrm{m} / \mathrm{s})$, (c) static temperature $(\mathrm{K})$, and $(\mathrm{d})$ static pressure $(\mathrm{Pa})$, of Model A

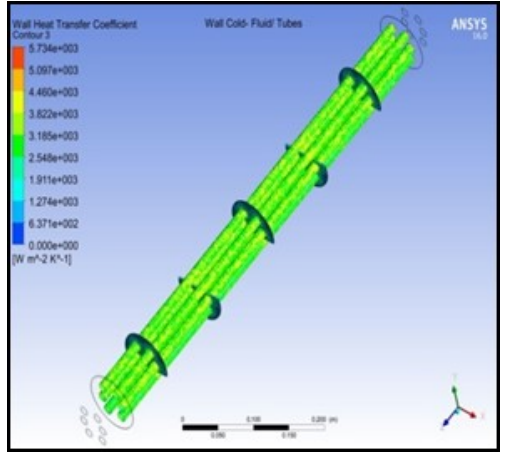

(a)

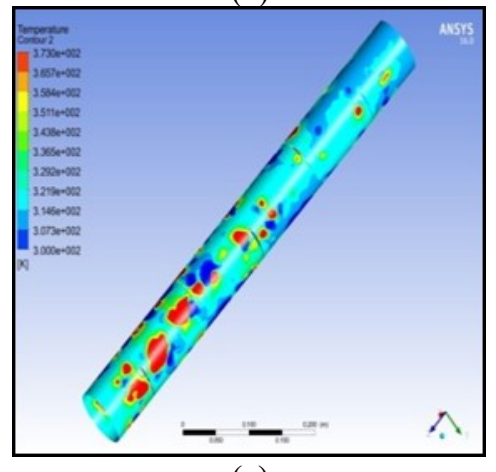

(c)

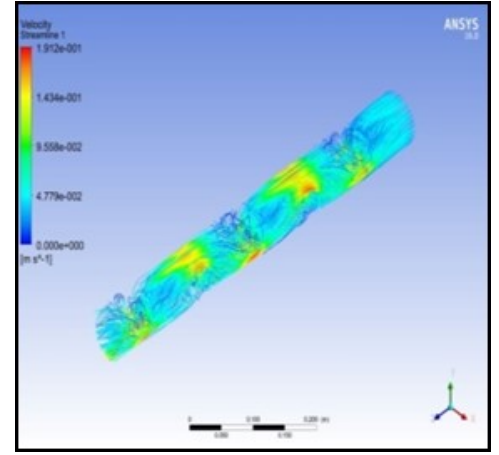

(b)

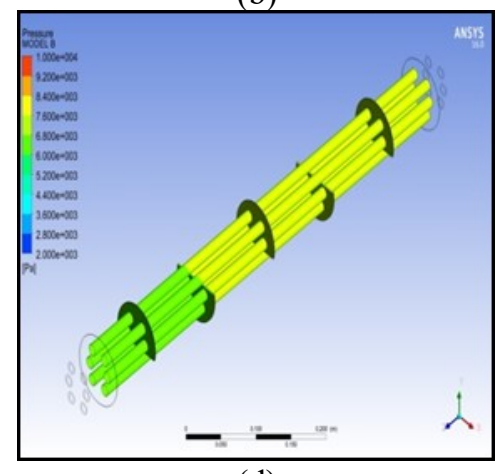

(d)

Figure 8. (a) Wall heat transfer cofficient $\left(\mathrm{W} / \mathrm{m}^{2} \mathrm{k}\right)$, (b) streamline velocity magnitude $(\mathrm{m} / \mathrm{s})$, (c) static temperature $(\mathrm{K})$ and $(\mathrm{d})$ static pressure $(\mathrm{Pa})$, of Model B 


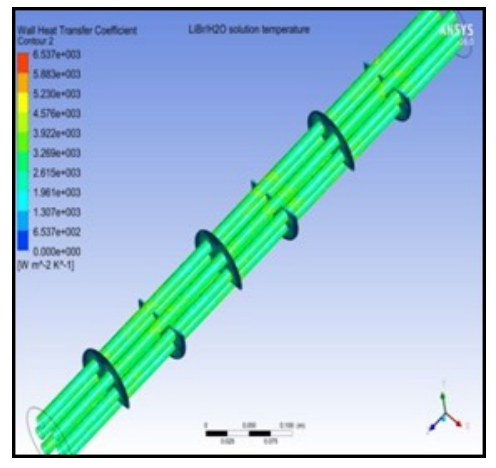

(a)

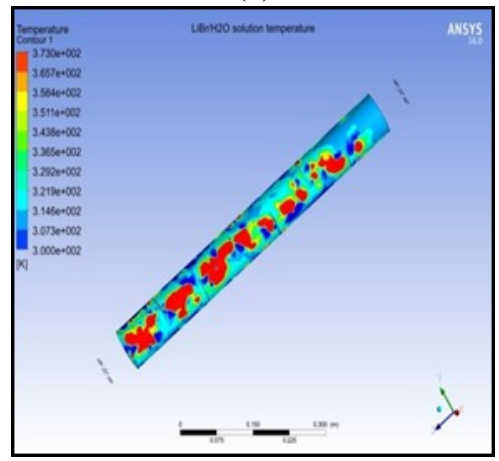

(c)

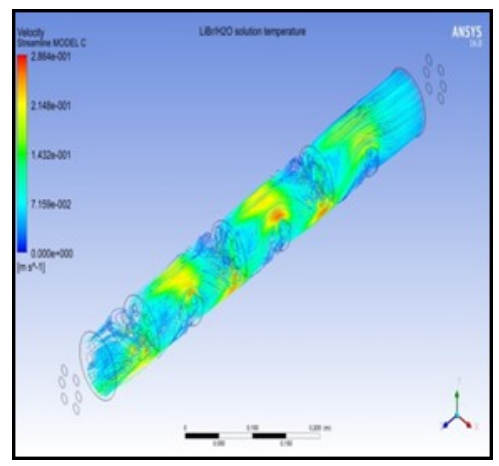

(b)

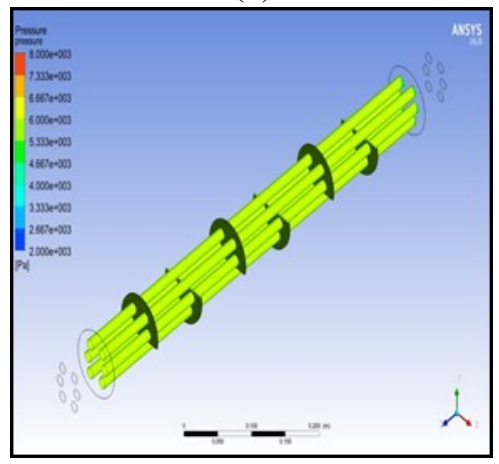

(d)

Figure 9 . (a) Wall Heat transfer cofficient $\left(\mathrm{W} / \mathrm{m}^{2} \mathrm{k}\right)$, (b) Streamline Velocity magnitude $(\mathrm{m} / \mathrm{s})$, (c) static temperature $(\mathrm{K})$, and $(\mathrm{d})$ static pressure $(\mathrm{Pa})$, of Model $\mathrm{C}$

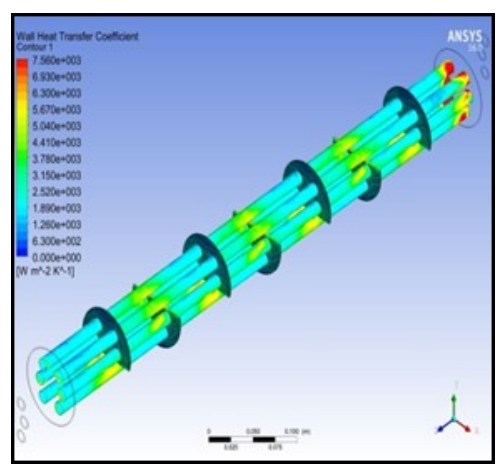

(a)

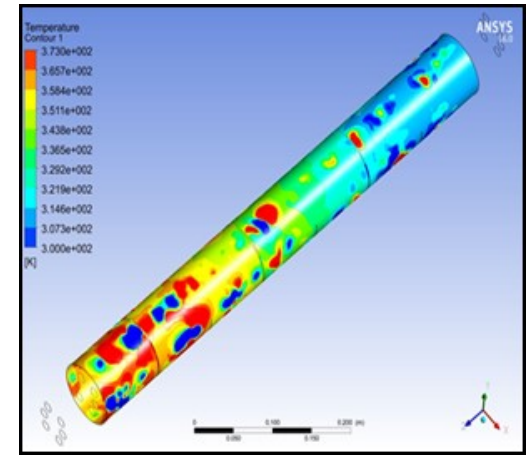

(c)

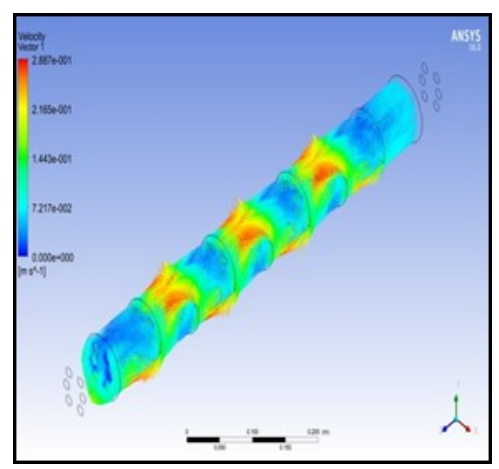

(b)

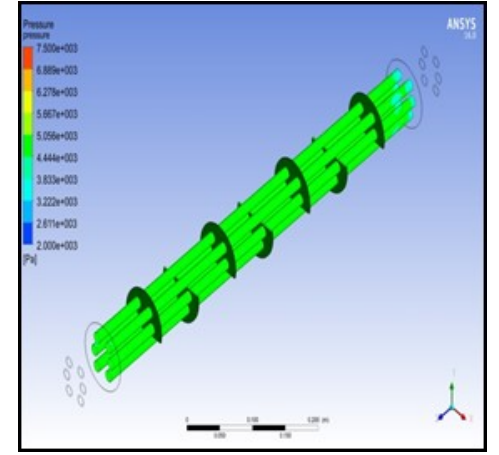

(d)

Figure 10. (a) Wall heat transfer cofficient $\left(\mathrm{W} / \mathrm{m}^{2} \mathrm{k}\right)$, (b) streamline velocity magnitude $(\mathrm{m} / \mathrm{s})(\mathrm{c})$ static temperature $(\mathrm{K})$, and (d) static pressure $(\mathrm{Pa})$, of Model D 
It is inferential from the figures that with decrease in the baffle distance, the wall heat transfer coefficient increases (as visible from increasing trend Model A to Model D). The lowest value of heat transfer coefficient, possessed by Model A is $2771 \mathrm{~W} / \mathrm{m}^{2} \mathrm{k}$ whereas the highest value, possessed by Model D is $4100 \mathrm{~W} / \mathrm{m}^{2} \mathrm{k}$ which is $48 \%$ higher than that of Model A. Similarly, the stream velocity has increased by about $36 \%$ from Model A to Model $\mathrm{D}$, due to decreasing baffle spacing. The static pressure has decreased by $27 \%$ from Model A to Model D. This is because of frictional losses, however it has consequently improved the heat transfer coefficient due to increased static temperature in $\mathrm{LiBr} / \mathrm{H}_{2} \mathrm{O}$ fluid to the required temperature of $90^{\circ} \mathrm{C}$ (outlet of cold fluid). Among all the four models, Model D shows the best result as per the CFD analysis.

Figure 11 shows the temperature gradient at the entry and exit of the generator model D. Figure 11(a) shows entry of $\mathrm{LiBr} / \mathrm{H}_{2} \mathrm{O}$ solution in the shell and exit of hot water inside the tube. Figure 11(b) shows entry of hot water and exit of $\mathrm{LiBr} / \mathrm{H}_{2} \mathrm{O}$ solution. It can be seen that at the entry, the $\mathrm{LiBr} / \mathrm{H}_{2} \mathrm{O}$ solution in the shell domain has around temperature $313 \mathrm{~K}$ at input boundary condition as (VAS) cycle design which is sufficient to generate vapors. However, as the heat is exchanged between hot water and $\mathrm{LiBr} / \mathrm{H}_{2} \mathrm{O}$ downstream the tubes, the $\mathrm{LiBr} / \mathrm{H}_{2} \mathrm{O}$ becomes sufficiently hot with average temperature of $363 \mathrm{~K}$.
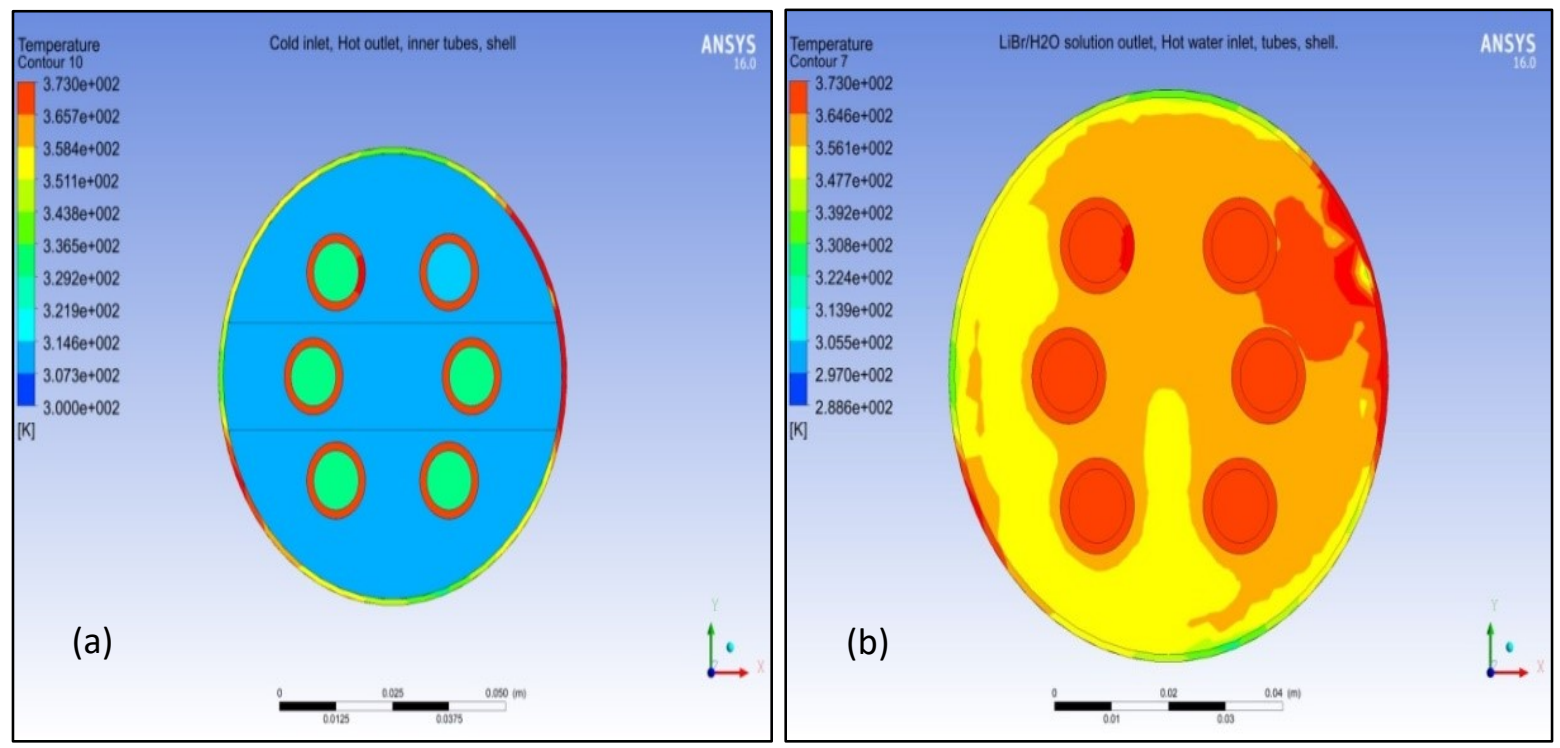

Figure 11. (a) Entry and (b) Exit side view of Model D showing static temperature of fluids

Figure 12(a) shows the plot of static temperature in Model D at inlet and outlet of cold fluid $\left(\mathrm{LiBr} / \mathrm{H}_{2} \mathrm{O}\right)$ solution, flowing through shell side at $313 \mathrm{~K}$. As the fluid flow through the shell, the heat get absorbed from the hot fluid flowing inside the tube of the generator heat exchanger. The cold fluid outlet has an average value of static temperature of $363 \mathrm{~K}$. The static temperature in cold fluid domain increases by $15.97 \%$. Further, the static temperature at inlet of hot fluid $\left(\mathrm{H}_{2} \mathrm{O}\right)$ is $373 \mathrm{~K}$ and average value at the outlet is around $326 \mathrm{~K}$. Similarly, Figure 12(b) shows the velocity magnitude in fluid cell zone condition at inlet and outlet of hot and cold fluid. The figure depicts that how the velocity increases while flowing along the length of shell in between the baffle plates, the average value of velocity at inlet and outlet are $0.041 \mathrm{~m} / \mathrm{s}$ and $0.045 \mathrm{~m} / \mathrm{s}$, respectively. 

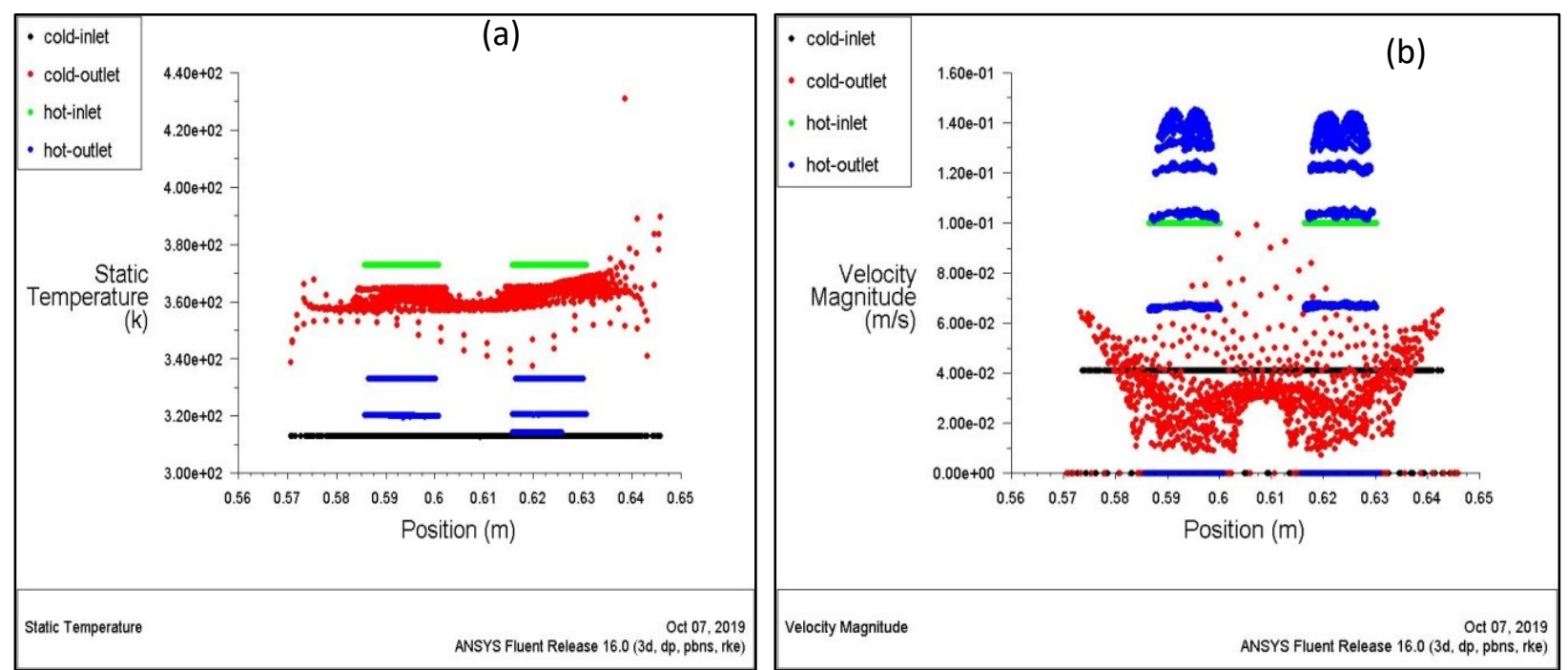

Figure 12. Comparison between inlets and outlets of hot and cold fluid for model D showing (a) Static temperature and (b) Velocity magnitude, along the length of the tube.

Figure 13 shows the rise in static temperature and variation in velocity magnitude of cold fluid $\left(\mathrm{liBr} / \mathrm{H}_{2} \mathrm{O}\right)$ while flowing inside the generator heat exchanger along the flow direction in model A.

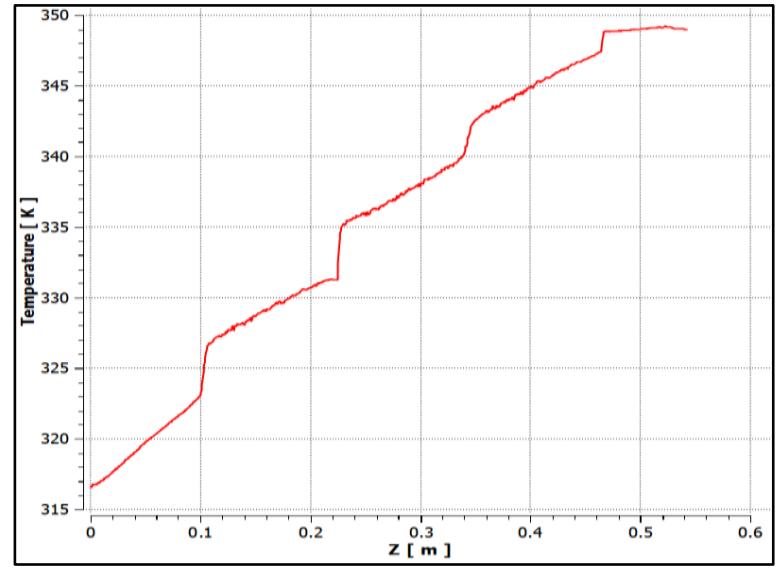

(a)

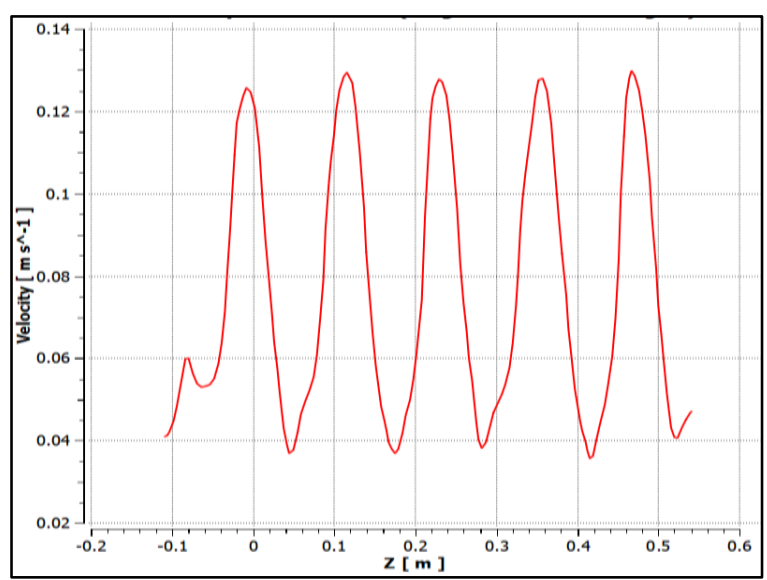

(b)

Figure 13. Cold fluid $\left(\mathrm{LiBr} / \mathrm{H}_{2} \mathrm{O}\right)$ in Model A, comparison (a) Static temperature and (b) Velocity magnitude to length of generator heat exchanger ( $\mathrm{Z}$ direction)

Similarly, Figure 14 shows the rise in static temperature and change in velocity magnitude during the flow of cold fluid in Model D. 


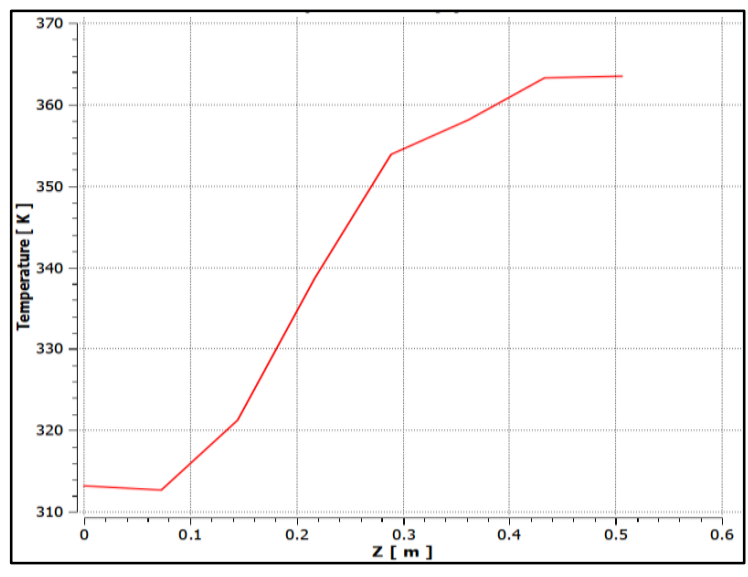

(a)

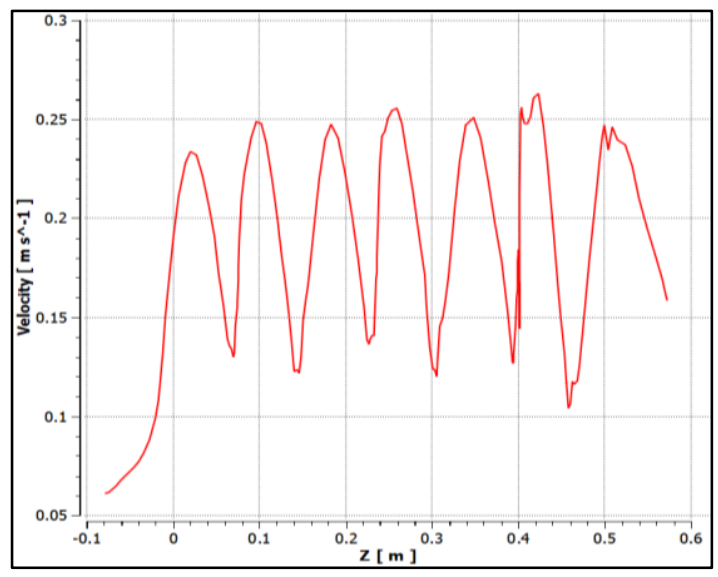

(b)

Figure 14. Cold fluid ( $\mathrm{LiBr} / \mathrm{H} 2 \mathrm{O})$ in Model D, comparison (a) Static temperature and (b) Velocity magnitude to length of generator heat exchanger ( $\mathrm{Z}$ direction)

From above figures, it can be noticed that the velocity fluctuates as the fluid passes between the baffle plates inside the shell. The values for static temperature and velocity magnitude can be observed corresponding to the two models (Model A and Model D), which were chosen relating to largest and smallest baffles space, respectively.

Table 6. Summary of CFD Results of Different models for different baffle spacing with 25\% baffle cut

\begin{tabular}{|l|c|c|c|c|c|}
\hline Generator & Fluids & Model A & Model B & Model C & Model D \\
\hline \multirow{2}{*}{ Outlet fluid average static Temperature $(\mathrm{K})$} & $\mathrm{LiBr} / \mathrm{H}_{2} \mathrm{O}$ & 348.75 & 350.32 & 358 & 363.33 \\
\cline { 2 - 6 } & Hot water & 338.14 & 339.98 & 331.12 & 326.09 \\
\hline $\begin{array}{l}\text { Average values of wall Heat transfer } \\
\text { coefficient }\left(\mathrm{W} / \mathrm{m}^{2} \mathrm{k}\right)\end{array}$ & Tube side & 2771.23 & 2898 & 3610.49 & 4100 \\
\hline Average value of static Pressure $(\mathrm{Pa})$ & $\mathrm{LiBr} / \mathrm{H}_{2} \mathrm{O}$ & 6271.48 & 6161.23 & 5692.45 & 4537.41 \\
\hline Average values of Velocity Magnitude $(\mathrm{m} / \mathrm{s})$ & $\mathrm{LiBr} / \mathrm{H}_{2} \mathrm{O}$ & 0.033 & 0.039 & 0.043 & 0.045 \\
\hline
\end{tabular}

The simulation results obtained using CFD analysis, were validate by comparing their values with theoretical results (obtained using Kern method). Though these values do not match closely, the trend of the variation is same in both the cases, which is sufficient to indicate the optimal design parameters.

Table 7. Comparison of theoretical and simulated temperature at different sections along the length

\begin{tabular}{|c|c|c|c|c|c|c|}
\hline Temperature & Length (m) & Theoretical & \multicolumn{5}{|l|}{ Temperature (K) } \\
\cline { 3 - 7 } & & & & & \\
\hline & & & Model A & Model B & Model C & Model D \\
\hline$T_{h, i}$ & 0.766 & 373 & 373 & 373 & 373 & 373 \\
\hline$T_{h, o}$ & 1.532 & 338 & 338.14 & 335.98 & 331.12 & 326.09 \\
\hline$T_{c, i}$ & 0.00 & 313 & 313 & 313 & 313 & 313 \\
\hline$T_{c, o}$ & 0.766 & 347 & 348.75 & 350.32 & 358 & 363.33 \\
\hline
\end{tabular}

Table 7 shows the validation of simulated temperature values of different models with theoretical results. The variation corresponding to Model D is $4.7 \%$ at outlet of cold fluid (lithium bromide water solution). This deviation may be due to difference in the velocity magnitude incurred by variation in baffle spacing used in actual simulation. Figure 15 below shows a simpler view of the validation presented in Table 7, above. 


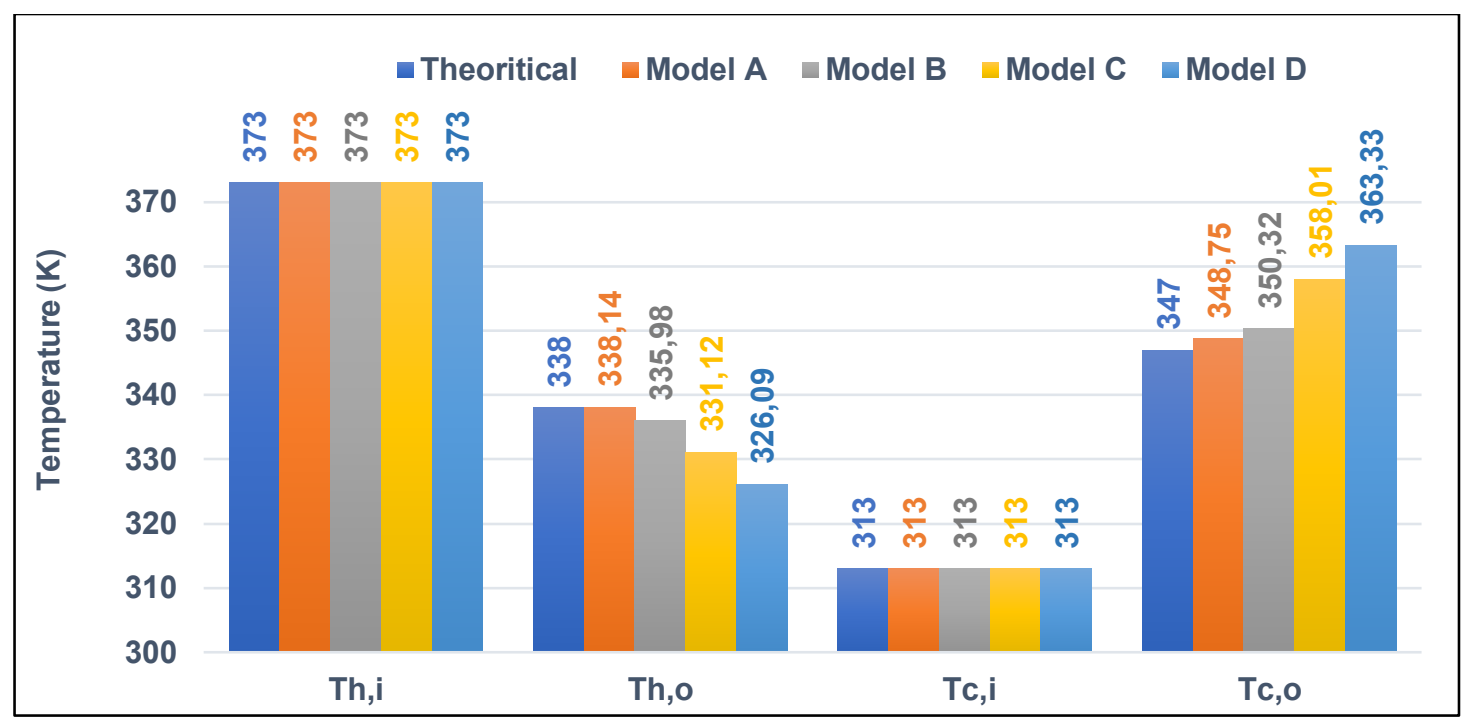

Figure 15. Comparison of theoretical and experimental results for different design models of generator heat exchanger

\section{CONCLUSION}

In tube-shell type generator heat exchanger, reducing the baffle spacing increases the heat transfer coefficient. The lower limit for the baffle spacing has been set by the TEMA Standards in the range, 0.2 to 1 times of the inside shell diameter. Contrarily, if the baffle spacing is large, the heat transfer coefficient is small. Moreover, large baffle spacing promotes longitudinal fluid flow which is considered less efficient compared to cross flow. This also leads to lesser unsupported tube length which makes the design less strong and more prone to failure due to buckling and vibration.

In this study we presented a detailed description of optimizing the generator heat exchanger of absorption system (VAS) using CFD simulation. Lithium bromide/water was taken as an absorbent- refrigerant pair. The effects of variable baffle distance of the generator heat exchanger on wall heat transfer coefficient, Reynolds number and static pressure have been analyzed, corresponding to four models. It was found that the model with the smallest baffle distance has the highest wall heat transfer coefficient which is attributed to high turbulence acting in the small spacing of the heat exchanger. By reducing the baffle space from $137 \mathrm{~mm}$ to $101 \mathrm{~mm}$, an increase in the wall heat transfer coefficient of $48 \%$ was observed. Likewise, an increase in velocity by $36 \%$ and drop in static pressure by $27 \%$ were seen. Similar trend was observed in the theoretical results; however, the theoretical values differ from CFD results. This is because the theoretical calculations are based on normal pressure of $\mathrm{LiBr}-\mathrm{H}_{2} \mathrm{O}$ solution, while, the CFD results are based on four cell zone condition, tubes and shell solid material (copper and steel), and cold fluid $\left(\mathrm{LiBr} / \mathrm{H}_{2} \mathrm{O}\right)$ solution and hot fluid (water). The CFD analysis was done using double precision and 2 processes method under vacuum pressure which represents the actual working condition (to create vapor at low boiling point) and hence, provides more accurate results.

\section{NOMENCLATURE}

A Tube cross sectional area, $m^{2}$

$A_{\text {req }} \quad$ Required surface area of tube, $m^{2}$

$A_{s} \quad$ Cross flow area at shell side, $m^{2}$

$C_{p} \quad$ Specific heat at constant pressure of hot/cold fluid, $\mathrm{J} / \mathrm{kgK}$

$C \quad$ Tube clearance, $m$

$D_{e} \quad$ Equivalent diameter, $m$

$D_{s} \quad$ Inside shell diameter, $m$

$D_{i} \quad$ Inside tube diameter, $m$ 
Journal of Thermal Engineering, Research Article, Vol. 6, No. 4, pp. 440-459, July, 2020

\begin{tabular}{|c|c|}
\hline$d_{o}$ & Outside tube diameter, $m$ \\
\hline$F_{T}$ & Correction factor \\
\hline$f_{i}$ & Friction factor on tube side \\
\hline$f_{o}$ & Friction factor on shell side \\
\hline$G_{S}$ & Mass velocity of shell side fluid, $\mathrm{kg} / \mathrm{m}^{2} \mathrm{~s}$ \\
\hline$h_{i}$ & Convection heat transfer Coefficient of tube side, $\mathrm{W} / \mathrm{m}^{2} \mathrm{~K}$ \\
\hline$h_{o}$ & Convection heat transfer Coefficient of shell side, $\mathrm{W} / \mathrm{m}^{2} \mathrm{~K}$ \\
\hline jH & Colburn factor \\
\hline$K_{w}$ & Thermal conductivity of tube material, $\mathrm{W} / \mathrm{mK}$ \\
\hline$K_{f i} / K_{f o}$ & Thermal conductivity of tube side \& shell side fluid, $\mathrm{W} / \mathrm{mK}$ \\
\hline$L_{T}$ & Tube length, $m$ \\
\hline$L_{B}$ & Baffle- spacing, $m$ \\
\hline$\dot{m}_{h} / \dot{m}_{c}$ & Mass flow rate of hot \& cold fluid, $\mathrm{kg} / \mathrm{s}$ \\
\hline$N_{b}$ & Number of baffles \\
\hline$n_{p}$ & Number of tube passes \\
\hline$n_{t}$ & Number of tubes \\
\hline$N u_{D}$ & Nusselt number of tube side fluid \\
\hline$O S$ & Over surface, $\%$ \\
\hline$O C$ & Overall heat transfer coefficient, $\%$ \\
\hline Od & Over design, $\%$ \\
\hline $\operatorname{Pr}$ & Prandtl number \\
\hline$\Delta P_{S}$ & Shell side Pressure drop, $N / m^{2}$ \\
\hline$\Delta P_{T}$ & Tube side pressure drop, $N / m^{2}$ \\
\hline$\Delta P_{T r}$ & Tube side return pressure drop, $\mathrm{N} / \mathrm{m}^{2}$ \\
\hline$P_{T}$ & Tube pitch size, $m$ \\
\hline$q$ & Heat transfer rate, $W$ \\
\hline$R_{d s} / R_{d h}$ & Fouling factor of solution $\&$ hot fluid \\
\hline$R$ & Heat capacity rate ratio \\
\hline$R e_{i} / R e_{o}$ & Reynolds number of tube $\&$ shell side fluid \\
\hline$T_{c, i}$ & Inlet temperature of cold fluid, ${ }^{\circ} \mathrm{C}$ \\
\hline$T_{c, o}$ & Outlet temperature of cold fluid, ${ }^{\circ} \mathrm{C}$ \\
\hline$T_{h, i}$ & Inlet temperature of hot fluid, ${ }^{\circ} \mathrm{C}$ \\
\hline$T_{h, o}$ & Outlet temperature of hot fluid, ${ }^{\circ} \mathrm{C}$ \\
\hline$\Delta T_{i m}$ & Log mean temperature difference, ${ }^{\circ} \mathrm{C}$ \\
\hline$U_{C}$ & Clean surface Overall heat transfer coefficient, $\mathrm{W} / \mathrm{m}^{2} \cdot \mathrm{K}$ \\
\hline$U_{o, c a l}$ & Calculated heat transfer co-efficient, $W / m^{2} \cdot K$ \\
\hline$U_{\text {assm }}$ & Assumed Overall heat transfer co-efficient, $\mathrm{W} / \mathrm{m}^{2} \cdot K$ \\
\hline$U_{m}$ & Mean velocity of tube(inside) side fluid per pass, $\mathrm{m} / \mathrm{s}$ \\
\hline$v_{i}$ & Mean velocity of tube side fluid $\mathrm{m} / \mathrm{s}, \mathrm{m} / \mathrm{s}$ \\
\hline$\mu_{i} / \mu_{o}$ & Dynamic viscosity of tube\& shell side fluid, $N \mathrm{~s} / \mathrm{m}^{2}$ \\
\hline$\rho_{i} / \rho_{o}$ & Density of tube $/$ shell side fluid, $\mathrm{kg} / \mathrm{m}^{3}$ \\
\hline$\varphi_{s}$ & Viscosity correction factor for shell side fluid \\
\hline
\end{tabular}

\section{REFERENCES}

[1] S. A. Mohamed, M. N. Karimi, "Simulation of lithium bromide- water (LiBr-H2O) vapor absorption system (VAS) powered by solar flat plate collector (SFPC)", IOP Conf. Series: Materials Science and Engineering 691 (2019) 012031, doi:10.1088/1757-899X/691/1/012031.

[2] C. Somers, A. Mortazavi, Y. Hwang, (2011). Modeling water/lithium bromide absorption chillers in ASPEN Plus. Applied Energy 88, 4197-4205.

[3] Aphornratana. S, Srikhirin. P. A review of absorption refrigeration technologies, Renew sustain energy Rev 2001: 5:343-72. 
[5] G.A. Florides, S.A. Tassou, (2003). Design and construction of a $\mathrm{LiBr}-$ water absorption machine, Energy Conversion and Management 44, 2483-2508

[6] Siamak Hoseinzadeh, Mohammad H. Zakeri, A. Shirkhani, and Ali J. Chamkha "Analysis of energy consumption improvements of a zero-energy building in a humid mountainous area". Journal of Renewable and Sustainable Energy. 11 (2019), doi:10.1063/1.5046512

[7] Ali J. Chamkha and Siamak Hoseinzadeh, Numerical investigation of rectangular thermal energy storage units with multiple phase change materials, Journal of Molecular Liquids, 271, 655-660 (2018).

[8] S. Hoseinzadeh, A. Moafi, A. Shirkhani and Ali J. Chamkha, "Numerical validation heat transfer of rectangular cross-section porous fins". Journal of Thermophysics and Heat Transfer. 33, 698-704 (2019). https://doi.org/10.2514/1.T5583.

[9] S. Hoseinzadeh, P. S. Heyns, A. J. Chamkha and A. Shirkhani, "Thermal analysis of porous fins enclosure with the comparison of analytical and numerical methods". Journal of Thermal Analysis and Calorimetry. 138, 727-735 (2019). https://doi.org/10.1007/s10973-019-08203-x

[10] Ahmed Elgafy and Osama Mesalhy and Khalid Lafdi, "Numerical study for enhancing the thermal conductivity of phase change material (PCM) storage using high thermal conductivity porous matrix", Energy Conversion and Management 46 (2005) 847-867.

[11] R. Ghasemiasl, S. Hoseinzadeh, and M. A. Javad, Numerical Analysis of Energy Storage Systems Using Two Phase-Change Materials with Nanoparticles. Journal of Thermophysics and Heat Transfer. 32, 440 448 (2018). https://doi.org/10.2514/1.T5252

[12] Mohammad Esmaeil, Siamak Hoseinzadeh and Yousef Nezhad, Mathematical modelling and simulation of a solar water heater for an aviculture unit using MATLAB/ SIMULINK, Journal of renewable and sustainable energy 9, 063702 (2017), doi:10.1063/1.5010828.

[13] Siamak Hoseinzadeh and Reza Azad, Simulation and optimization of a solar-assisted heating and cooling system for a house in Northern of Iran, Journal of Renewable and Sustainable Energy. 9(2017), doi: $10.1063 / 1.5000288$.

[14] H. Kariman, S. Hoseinzadeh and P. Stephan Heyns, Energetic and exergetic analysis of evaporation desalination system integrated with mechanical vapor recompression circulation. Case Studies in Thermal Engineering, 100548 (2019).

[15] H. Kariman, S. Hoseinzadeh, A. Shirkhani, P. S. Heyns and J. Wannenburg, Energy and economic analysis of evaporative vacuum easy desalination system with brine tank. Journal of Thermal Analysis and Calorimetry. https://doi.org/10.1007/s10973-019-08945-8

[16] S. Hoseinzadeh, P.S. Heyns and H. Kariman, "Numerical investigation of heat transfer of laminar and turbulent pulsating Al2O3/water nanofluid flow", International Journal of Numerical Methods for Heat \& Fluid Flow, Vol. ahead-of-print No. ahead-of-print. doi.org/10.1108/HFF-06-2019-0485

[17] S. Hoseinzadeh, S.A.R. Sahebi, R. Ghasemiasl, and A.R. Majidian, "Experimental analysis to improving thermosyphon (TPCT) thermal efficiency using nanoparticles/based fluids (water)". European Physical Journal Plus. 132(2017), doi:10.1140/epjp/i2017-11455-3.

[18] M.M. Sarafraz and M. Arjomandi, Thermal performance analysis of a microchannel heat sink cooling with copper oxide-indium $(\mathrm{CuO} / \mathrm{In})$ nano-suspensions at high-temperatures, Applied Thermal Engineering 137 (2018) 700-709.

[19] M. M. Sarafraz, Mohammad Reza Safaei, Zhe Tian Thermal assessment of nano-particulate graphenewater/ethylene glycol (WEG 60: 40) nano-suspension in a compact heat exchanger, Energies 2019, 12, 1929; doi:10.3390/en12101929

[20] M.M. Sarafraz and M.R. Safaei, Diurnal thermal evaluation of an evacuated tube solar collector (ETSC) charged with graphene nanoplatelets-methanol nano-suspension, renewable energy 142 (2019) 364- 372.

[21] E. Salari , S. M. Peyghambarzadeh , M.M. Sarafraz and F. Hormozi, "Boiling thermal performance of TiO2 aqueous nanofluids as a coolant on a disc copper block", Periodica Polytechnica Chemical Engineering, DOI: 10.3311/PPch.8262 
Journal of Thermal Engineering, Research Article, Vol. 6, No. 4, pp. 440-459, July, 2020

[22] M.M. Sarafraz, F. Hormozi, "Pool boiling heat transfer to dilute copper oxide aqueous nanofluids", International Journal of Thermal Sciences 90 (2015) 224-237.

[23] Robert A. Taylor, P. Phelan, Pool boiling of nanofluids: comprehensive review of existing data and limited new data, Int. J. Heat Mass Trans. 52 (2009) 5339e5347.

[24] C. P. Arora 2009 Refrigeration and air conditioning, McGram- Hill book third edition.

[25] Theodorel. Bergman, Frank P. Incropera, 2012. Fundamentals of heat and mass transfer, MPS Limited, a Macmillan Company, Seventh Edition book.

[26] D. Q. Kern, Process Heat Transfer, McGraw-Hill Book Company, Int. ed. 1965.

[27] Mhrd, Nptel, Chemical Engineering - Chemical Engineering Design - II Joint process design of shell and tube exchanger for two phase heat transfer Joint initiative of IITs and IISc.

[28] Peters, M.S., Timmerhaus, K.D., and West, R.E., Plant Design and Economics for Chemical Engineers, McGraw-Hill, New York, 2003.

[29] A. S. Teja, S. M. Jeter, Thermophysical Property Data For Lithium Bromide/Water Solutions At Elevated Temperatures, Prepared For The American Society OF Heating, Refrigerating And Air-Conditioning Engineers Under Project 526-RP.

[30] L. Labra, D. Juarez-Romero, J. Siqueiros, 2016. Measurement of Properties of a Lithium Bromide Aqueous Solution for the Determination of the Concentration for a Prototype Absorption Machine, Applied Thermal Engineering, S1359-4311(16)32758 2:http://dx.doi.org. 